Supporting Information for

\title{
Plasma Cleaning and Self-Limited Welding of Silver Nanowire Films for
}

\section{Flexible Transparent Conductors}

Jianfang Liu $u^{\dagger}$, Yongjie Ge ${ }^{\dagger \dagger}$, Dumeng Zhang§, Mei Han ${ }^{\dagger}$, Moxia Li ${ }^{\dagger}$, Meng Zhang ${ }^{\dagger}$, Xidong Duan ${ }^{* \dagger}$, Zhilin Yang*,, , Jiawen $H u^{*, \dagger}$

†Hunan Key Laboratory of Two-Dimensional Materials, Advanced Catalytic Engineering Research Center of the Ministry of Education, and College of Chemistry and Chemical Engineering, Hunan University, Changsha 410082, China

$\S$ Department of Physics, Xiamen University, Xiamen 361005, China

*To whom correspondence should be sent. Prof. X. Duan: xidongduan@hnu.edu.cn; Prof.

Z. Yang: zlyang@xmu.edu.cn; and Prof. J.Hu: jwhu@hnu.edu.cn 


\section{Supplementary figures and table}

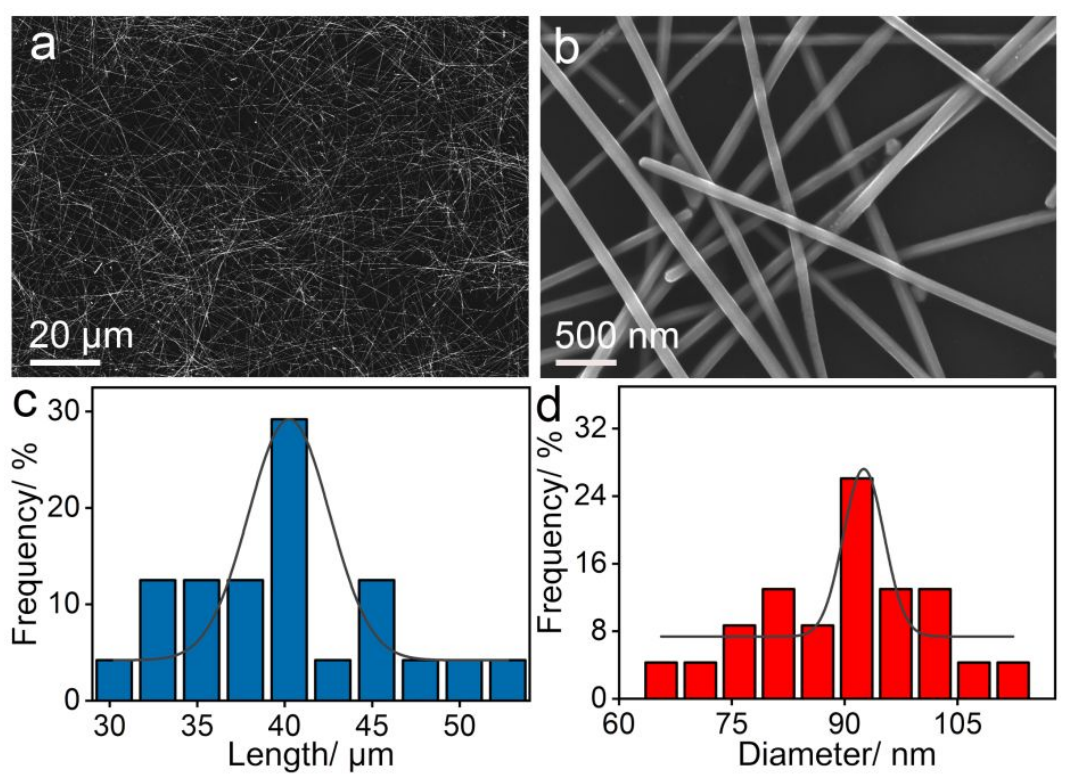

Figure S1. Characterizations of the synthesized Ag NWs. (a) Low- and (b) high-magnification SEM images and corresponding (c) length and (d) diameter distribution.
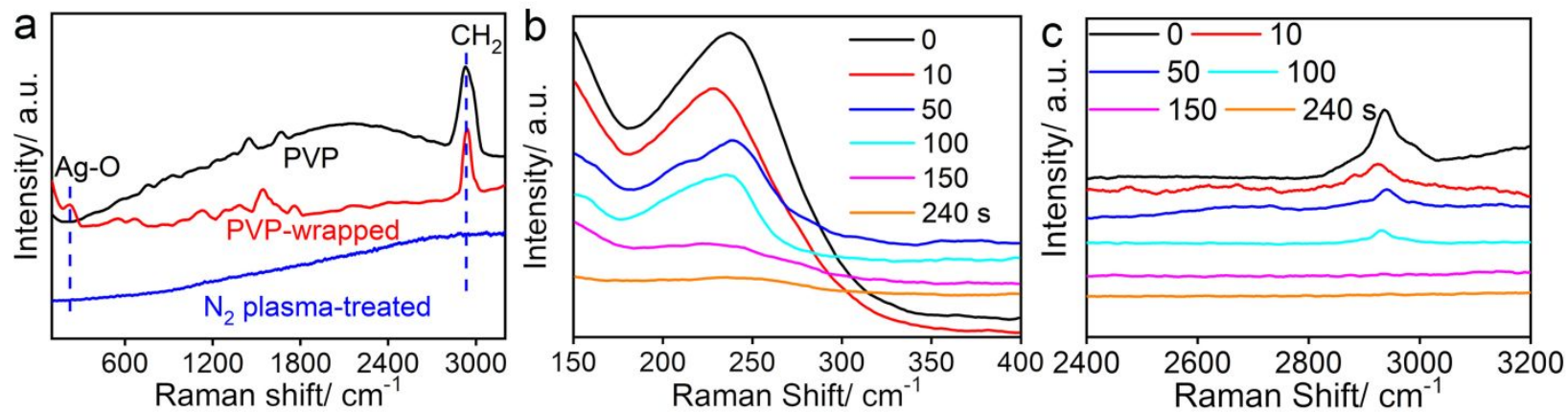

Figure S2. (a) Raman spectra for pure PVP, PVP-wrapped Ag NWs, and $\mathrm{N}_{2}$ plasma-treated Ag NWs (300 W for $4 \mathrm{~min}$ ) and Raman spectra over (b) a low spectral window and (c) a high spectral window for PVP-wrapped Ag NWs upon $\mathrm{N}_{2}$ plasma treatment at $300 \mathrm{~W}$ for different durations. 

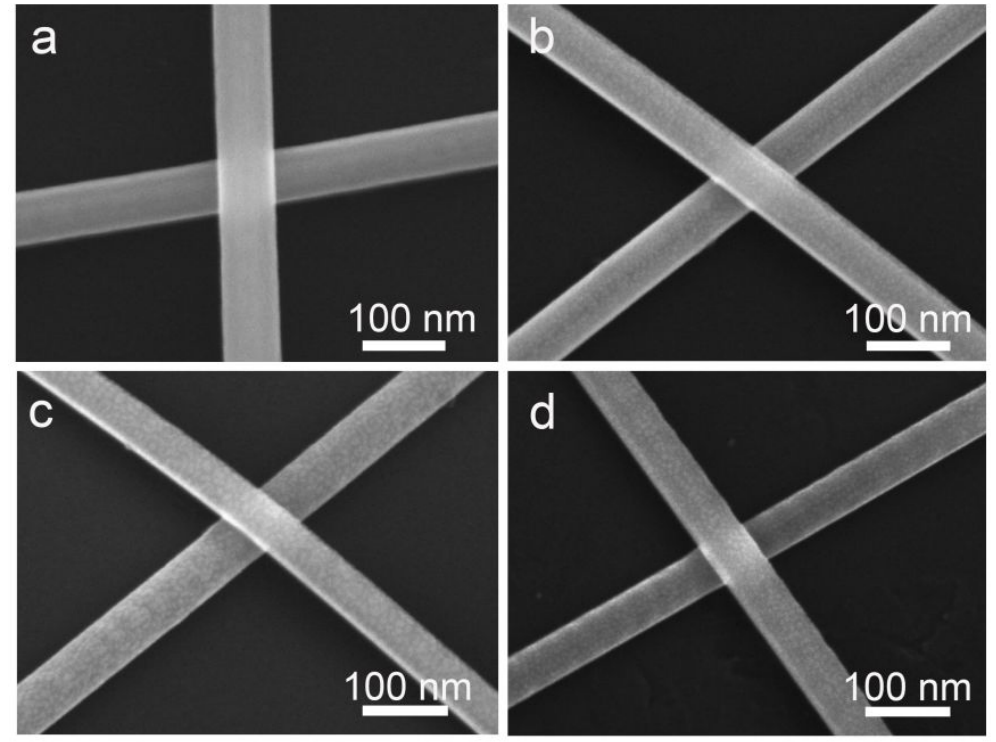

Figure S3. SEM images of a single NW/NW junction upon $\mathrm{N}_{2}$ plasma treatment at $300 \mathrm{~W}$ for (a) 4, (b) 6, (c) 8, and (d) 10 min.

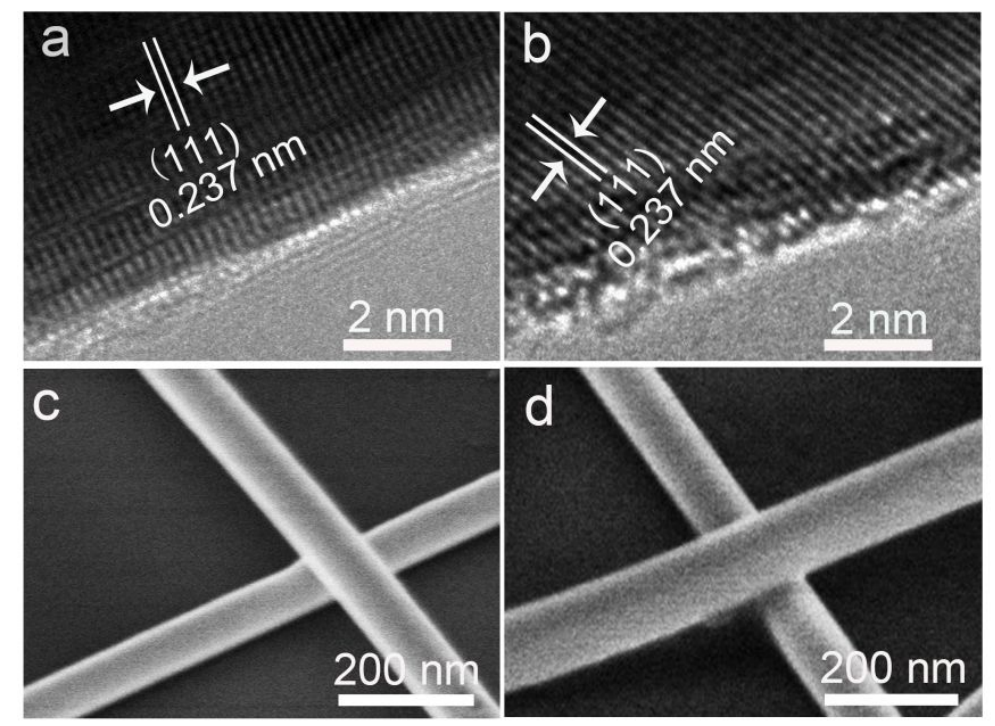

Figure S4. (a, b) HRTEM images of a single Ag NW upon (a) $\mathrm{H}_{2}$-Ar plasma treatment and (b) $\mathrm{O}_{2}$ plasma treatment at $300 \mathrm{~W}$ for 4 min and (c, d) SEM images of a single NW/NW junction upon (c) $\mathrm{H}_{2}$-Ar plasma treatment and (d) $\mathrm{O}_{2}$ plasma treatment at $300 \mathrm{~W}$ for 4 min. 

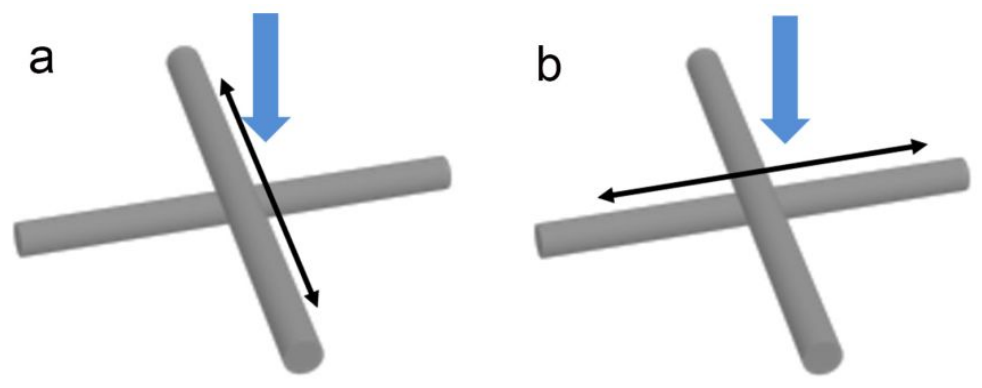

Figure S5. Two perpendicularly center-crossed Ag NWs (length, $2 \mu \mathrm{m}$; diameter, $80 \mathrm{~nm}$ ) under vertical illumination of the incident light polarized (a) parallel to and (b) perpendicular to the top Ag NW, used as models for FDTD simulations.
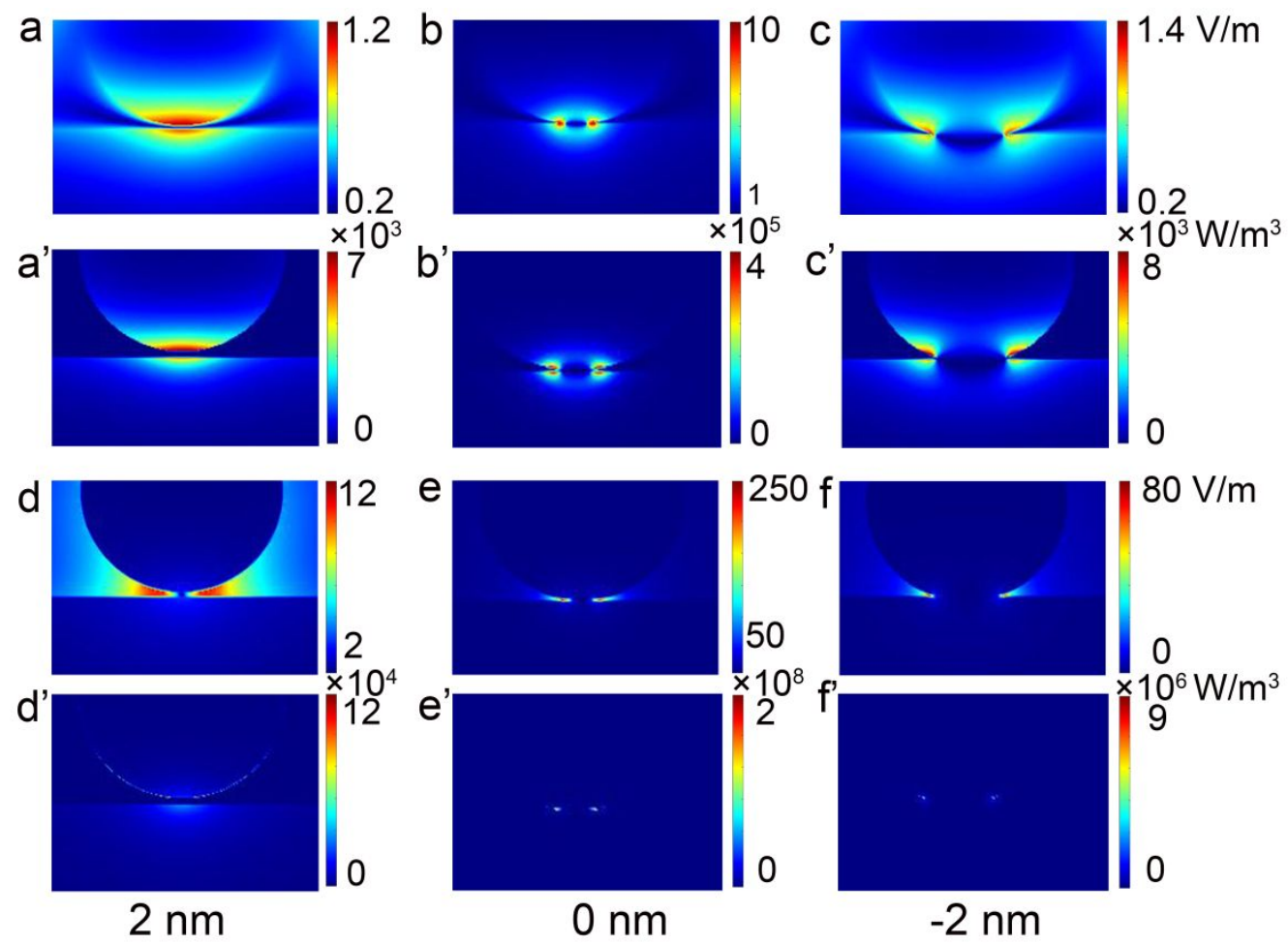

Figure S6. (a-c, d-f) Electric field distribution and (a'-c', d'-f') local heat converted around two perpendicularly crossed Ag NWs (length, $2 \mu \mathrm{m}$; diameter, $80 \mathrm{~nm}$ ) with a NW/NW gap of (a, a', d, and d') 2, (b, b', e, and e') 0 , and (c, c', f, and f') $-2 \mathrm{~nm}$, excited using a $590 \mathrm{~nm}$ light polarized (a-c, a'-c') parallel to and (d-f, d'-f') perpendicular to the top Ag NW. 


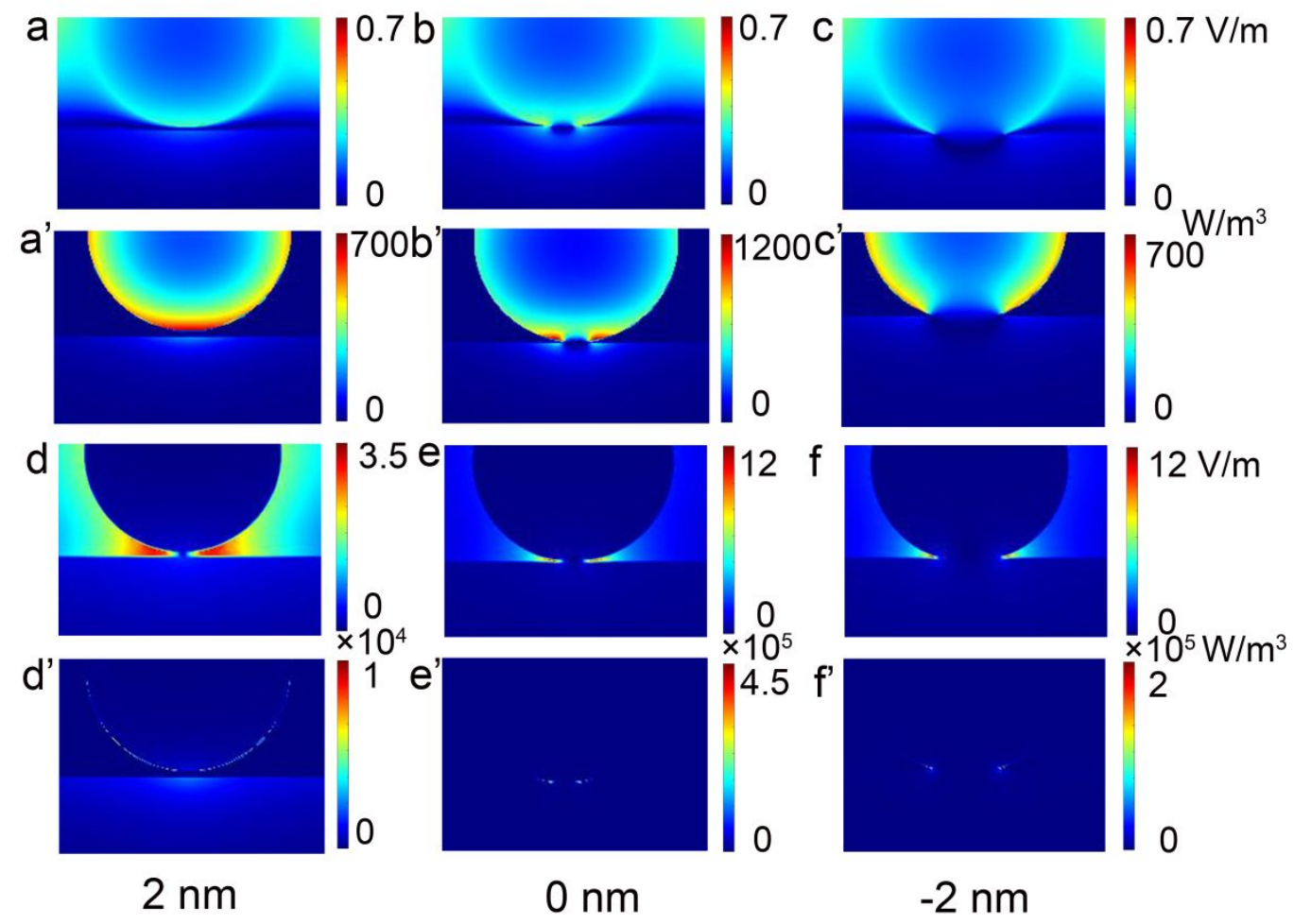

Figure S7. (a-c, d-e) Electric field distribution and (a'-c', d'-e') local heat converted around two perpendicularly crossed Ag NWs (length, $2 \mu \mathrm{m}$; diameter, $80 \mathrm{~nm}$ ) with a NW/NW gap of (a, a', d, and d') 2, (b, b', e, and e') 0, and (c, c', f, and f') $-2 \mathrm{~nm}$, excited using a $805 \mathrm{~nm}$ light polarized (a-c, a'-c') parallel to and (d-f, d'-f') perpendicular to the top Ag NW.

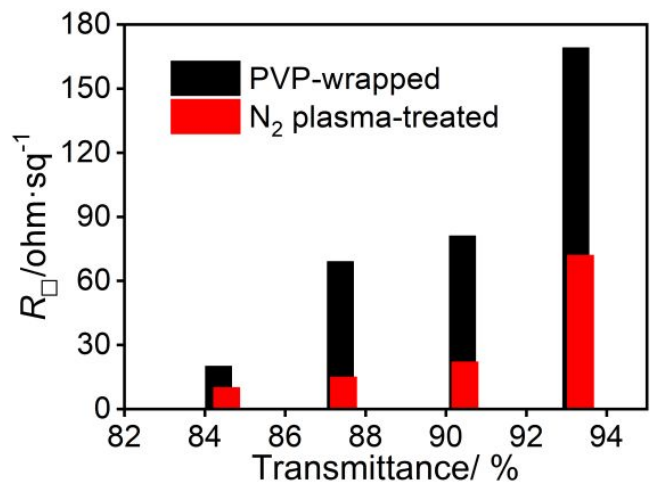

Figure S8. Sheet resistance and transmittance (@550 nm) variations for the PVP-wrapped Ag NW films before and after $\mathrm{N}_{2}$ plasma treatment at $300 \mathrm{~W}$ for $4 \mathrm{~min}$. 


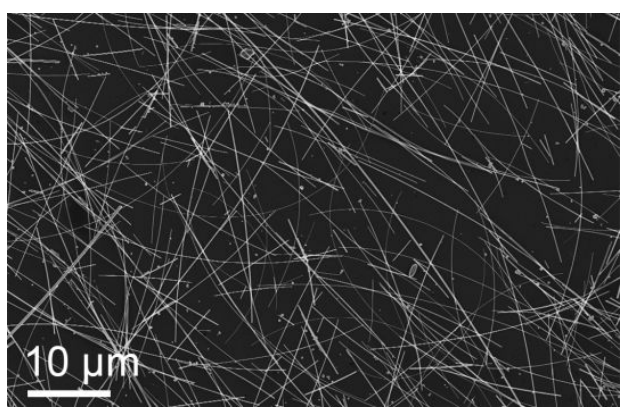

Figure S9. SEM image of the Ag NW film (transmittance, 85.41\%; sheet resistance, $34 \Omega / s q$ ) used for flexibility test.

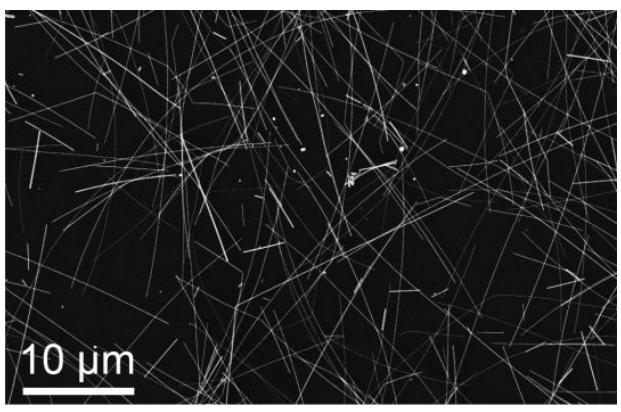

Figure S10. SEM image of the Ag NW film (transmittance, $89.95 \%$; sheet resistance, $89 \Omega / \mathrm{sq}$ ) in a typical transparent heater.

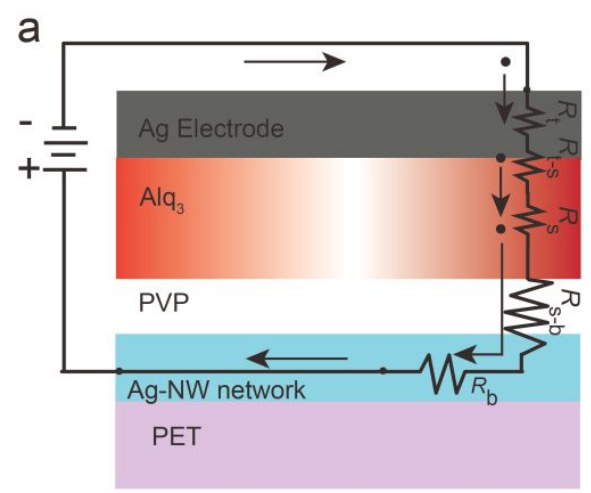

b

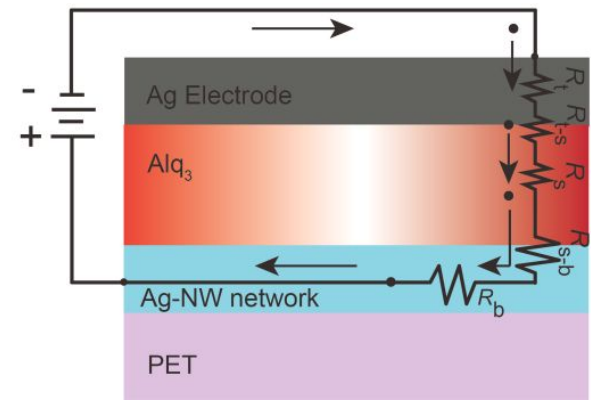

Figure S11. Equivalent electric circuit for the electron-only device constructed from (a) PVPwrapped and (b) $\mathrm{N}_{2}$ plasma-treated $\mathrm{Ag} \mathrm{NW}$ films using 8-hydroxyquinoline $\left(\mathrm{Alq}_{3}\right)$ as the semiconductor layer. 
Table S1. Electric field strength and heat converted on two perpendicularly center-crossed Ag NWs under vertical illumination of 375,590 , and $805 \mathrm{~nm}$ light polarized parallel to and perpendicular to the top Ag NW.

\begin{tabular}{|c|c|c|c|c|c|}
\hline \multirow{2}{*}{$\lambda(\mathrm{nm})$} & \multirow{2}{*}{$\begin{array}{l}\text { Gap } \\
(\mathrm{nm})\end{array}$} & \multicolumn{2}{|c|}{ Parallel } & \multicolumn{2}{|c|}{ Perpendicular } \\
\hline & & $\begin{array}{c}\text { Electrical } \\
\text { field }(\mathrm{V} / \mathrm{m})\end{array}$ & $\begin{array}{c}\text { Heat } \\
\left(\times 10^{3} \mathrm{~W} / \mathrm{m}^{3}\right)\end{array}$ & $\begin{array}{c}\text { Electrical } \\
\text { field }(\mathrm{V} / \mathrm{m})\end{array}$ & $\begin{array}{c}\text { Heat } \\
\left(\times 10^{5} \mathrm{~W} / \mathrm{m}^{3}\right)\end{array}$ \\
\hline \multirow{3}{*}{375} & 2 & 1.4 & 7.5 & 20.0 & 2.0 \\
\hline & 0 & 1.2 & 4.5 & 18.0 & 3.0 \\
\hline & -2 & 0.0 & 0.0 & 0.0 & 0.0 \\
\hline \multirow{3}{*}{590} & 2 & 1.2 & 7.0 & 12.0 & 1.2 \\
\hline & 0 & 10.0 & 400.0 & 250.0 & 2000.0 \\
\hline & -2 & 0.0 & 0.0 & 0.0 & 0.0 \\
\hline \multirow{3}{*}{805} & 2 & 0.7 & 0.7 & 3.5 & 0.1 \\
\hline & 0 & 0.7 & 1.2 & 12.0 & 4.5 \\
\hline & -2 & 0.0 & 0.0 & 0.0 & 0.0 \\
\hline
\end{tabular}

